\title{
AKTIVITAS ANTIFUNGI FRAKSI ETILASETAT AKAR SINGAWALANG (PETIVERIA ALLIACEA L.) TERHADAP ASPERGILLUS NIGER
}

\author{
Niken Indriyanti \\ Fakultas Farmasi Universitas Mulawarman, Samarinda \\ e-mail:niken@farmasi.unmul.ac.id
}

\begin{abstract}
Aspergillus niger is a mold that can infect respiratory tract in certain condition. Azoles are used to solve this infection. Drug development on antifungal drugs still continued, one of the resorce is from plant. A plant that widely studied as antifungi is singawalang (Petiveria alliacea L.). Activity of ethanol extract and fraction of singawalang roots on Aspergillus niger tested by microdilution broth method appropriate to Clinical and Laboratory Standard Institute (CLSI) standard. Microdilution test results showed that Singawalang roots extract has antifungal activity against Aspergillus niger with Minimum Inhibition Concentration (MIC) $32 \mu \mathrm{g} / \mathrm{mL}$ and Minimum Fungicidal Concentration (MFC) 1048 $\mu \mathrm{g} / \mathrm{mL}$. Fraction that has high activity against Aspergillus niger was ethylacetate fraction of Singawalang roots with MIC $128 \mu \mathrm{g} / \mathrm{ml}$ dan MFC $512 \mu \mathrm{g} / \mathrm{mL}$. The higher activity of the extract than the fraction was predicted as the impact of multiple compounds that have synergic activity. The growth profile of Aspergillus niger showed unconstant result and tends to descend. However, further research needed to ensure this effect.
\end{abstract}

Keywords: antifungal, microdilution, singawalang (Petiveria alliacea L.), Aspergillus niger

\begin{abstract}
ABSTRAK
Aspergillus niger merupakan kapang penginfeksi saluran pernafasan pada kondisi tertentu. Obat-obat golongan azol biasa digunakan untuk mengatasi infeksi ini. Pengembangan obat antifungi saat ini terus dilakukan, termasuk dari tanaman. Salah satu tanaman yang telah banyak diteliti memiliki efek antifungi adalah tanaman singawalang (Petiveria alliacea L.). Pengujian dilakukan dengan Broth Microdilution sesuai standar Clinical and Laboratory Standard Institute (CLSI). Ekstrak akar singawalang menghambat pertumbuhan Aspergillus niger dan memiliki KHM 32 ppm dan KFM 1048 ppm. Hasil dan Fraksi Ekstrak Akar Singawalang Terhadap Aspergillus niger pada fraksi etilasetat ekstrak etanol akar singawalang adalah Konsentrasi Hambat Minimum (KHM) $128 \mu \mathrm{g} / \mathrm{mL}$ dan Konsentrasi Fungisidal Minimum (KFM) $512 \mu \mathrm{g} / \mathrm{mL}$. KHM ekstrak yang lebih tinggi diduga karena senyawa yang bekerja sinergis. Profil pertumbuhan Aspergillus niger tidak konstan dan cenderung menurun mirip efek fungisida sehingga penelitian lanjutan diperlukan untuk memastikan efek tersebut.
\end{abstract}

Kata Kunci: Antifungi, mikrodilusi, singawalang (Petiveria alliacea L.), Aspergillus niger

\section{PENDAHULUAN}

Penyakit infeksi merupakan masalah besar di Indonesia karena iklim panas dan lembab sehingga bakteri, kapang dan khamir dapat berkembang dengan baik. Aspergillus niger adalah salah satu kapang yang dapat menimbulkan aspergillosis (Segismundo, 2008). Aspergillosis merupakan infeksi eksogen karena mikroba masuk dari 
lingkungan kedalam tubuh melalui sistem bronkhial atau melalui luka pada kulit/mukosa. Aspergillosis pulmonari invasif ditemukan pada pasien yang terkena neutropenia, AIDS dan setelah transplantasi organ (Kayser, 2005). Aspergillosis bronchopulmonary allergic ditandai dengan asma yang berkembang sampai bronko-spasme, eosinofilia, peningkatan $\operatorname{IgE}$ dan presipitin aspergillosis dalam darah. Aspergillosis invasif banyak terjadi pada pasien imunodefisiensi dengan neutropenia berat. Pada pasien ini terdeteksi adanya galactomannan dengan ELISA. Golongan azol dapat dipertimbangkan untuk mengatasi aspergillosis. Obat caspofungin dan echinocandin juga dapat digunakan. Angka kematian karena aspergillosis parah adalah lebih dari $50 \%$ (Tierney dkk., 2005). Untuk mengatasi masalah tersebut, pengembangan obat konvensional maupun dari bahan alam terus dilakukan.

Tanaman singawalang (Petiveria alliacea L.) termasuk dalam famili Phytolaccaceae. Dilaporkan bahwa akar singawalang mengandung senyawa polisulfida yang telah diuji efektif terhadap sejumlah fungi (Benevides, 2000). Karena aktivitasnya tersebut, pengujian efeknya dikembangkan terhadap Aspergillus niger.

\section{TUJUAN}

Menentukan efek akar singawalang terhadap Aspergillus niger

\section{METODE PENELITIAN}

Bahan Penelitian

Akar singawalang, biakan Aspergilllus niger murni, etanol, etilasetat, aquades, Potato Dextrose Broth (PDB), Potato Dextrose Agar (PDA), minyak zaitun, $\mathrm{NaCl}$ 0,9\% steril, dimetilsulfoksid (DMSO), ketokonazol.

\section{Alat Penelitian}

Gelas kimia, labu Erlenmeyer, rak tabung, batang pengaduk, gelas ukur, pipet tetes, pipet ukur, pipet volume, mikropipet $100 \mu \mathrm{L}, 5-50 \mu \mathrm{L}, 10 \mu \mathrm{L}$, cawan petri, jarum ose, bunsen, pelat mikro 96 lubang, LAF (Laminar Air Flow), tabung reaksi, tip, vial, eppendorf, sudip, oven, vortex, otoklaf, inkubator, kuvet, spektrofotometer.

\section{Prosedur Penelitian}

Sebanyak $100 \mu \mathrm{L}$ nutrient broth dimasukkan dalam pelat mikro pada kolom pertama (sebagai kontrol negatif). Suspensi jamur sebanyak $5 \mu \mathrm{L}$ ditambahkan ke dalam $10 \mathrm{~mL}$ nutrient broth kemudian diaduk dengan alat vortex. Sebanyak $100 \mu \mathrm{L}$ campuran tersebut dimasukkan dalam pelat mikro pada kolom kedua sampai kedua belas. Pada kolom kedua belas, ditambahkan $100 \mu \mathrm{L}$ larutan antibiotik / ekstrak dengan konsentrasi tertentu kemudian dihomogenkan. Dari kolom kedua belas, diambil $100 \mu \mathrm{L}$ kemudian dipindahkan ke kolom kesebelas. Pengenceran terus dilakukan sampai pada kolom ketiga yang akan memiliki konsentrasi terkecil. Pelat diinkubasi pada suhu $37^{\circ} \mathrm{C}$ selama $3 \times 24$ jam kemudian diamati bagian yang jernih (tidak ada pertumbuhan mikroba). Konsentrasi terkecil di mana tidak terlihat pertumbuhan mikroba ditetapkan sebagai MIC.

Sebanyak $5 \mu \mathrm{L}$ alikuot dari setiap bagian yang jernih dipindahkan dalam nutrient agar dan diinkubasi pada suhu $37{ }^{\circ} \mathrm{C}$ selama $3 \times 24$ jam kemudian diamati. Konsentrasi terendah di mana tidak terlihat adanya pertumbuhan mikroba ditetapkan sebagai minimum fungicidal concentration (MFC) atau Konsentrasi Fungisidal Minimum (KFM).

\section{HASIL DAN PEMBAHASAN}

Pengujian adanya aktivitas antijamur pada ekstrak etanol akar singawalang dan fraksinya dilakukan dengan metode mikro-dilusi yang merupakan metode standar Clinical and Laboratory Standard Institute. Pada pengujian ini digunakan pelat mikro 96 
well yang memungkinkan pengujian aktivitas antijamur dalam satu seri konsentrasi secara bersamaan.

Ekstrak akar singawalang menghambat pertumbuhan Aspergillus niger dan memiliki KHM 32 ppm dan KFM 1048 ppm.
Dari data tersebut, dilakukan pengujian lebih lanjut dengan memfraksinasi ekstrak uji menggunakan pelarut $n$-heksan, etilasetat dan etanol. Tiap-tiap fraksi diuji aktivitas antijamur dengan cara mikrodilusi seperti sebelumnya. Hasil pengujian fraksi ada pada tabel 2.

Tabel 1. Hasil Pengujian Efek Ekstrak etanol akar singawalang Terhadap Aspergillus niger

\begin{tabular}{|c|c|c|c|}
\hline \multicolumn{2}{|c|}{ Ketokonazol } & \multirow{2}{*}{\multicolumn{2}{|c|}{ Ekstrak etanol akar singawalang }} \\
\hline $\mathrm{KHM}(\mu \mathrm{g} / \mathrm{mL})$ & $\mathrm{KFM}(\mu \mathrm{g} / \mathrm{mL})$ & $\mathrm{KHM}(\mu \mathrm{g} / \mathrm{mL})$ & \\
\hline 16 & - & 32 & 1048 \\
\hline
\end{tabular}

Tabel 2. Hasil KHM dan KFM ( $\mu \mathrm{g} / \mathrm{mL})$ Fraksi Ekstrak Akar Singawalang Terhadap Aspergillus niger

\begin{tabular}{llllll}
\hline \multicolumn{5}{c}{ Fraksi ekstrak akar singawalang } \\
\hline \multicolumn{2}{c}{$n$-heksan } & \multicolumn{2}{c}{ etilasetat } & \multicolumn{2}{c}{ air } \\
\hline KHM & KFM & KHM & KFM & KHM & KFM \\
- & - & 128 & 512 & 512 & 512 \\
\hline
\end{tabular}

Tabel 3. Hasil Penghitungan Jumlah Koloni Aspergillus niger pada Pemberian Fraksi Etilasetat Akar Singawalang

\begin{tabular}{ccccc}
\hline \multirow{2}{*}{ Waktu (jam) } & \multicolumn{4}{c}{ Jumlah koloni mikroba (Log CFU/mL) } \\
& Kontrol & 4 MIC & 8MIC & Ketokonazol \\
\hline 0 & 3,2253 & 3,0645 & 3,0792 & 2,9031 \\
12 & 4,4942 & 4,1680 & 4,0777 & 3,5211 \\
24 & 4,2253 & 3,8195 & 4,0269 & 3,4742 \\
36 & 4,1679 & 3,9823 & 3,3766 & 3,0492 \\
48 & 4,2106 & 2,7482 & 3,8762 & 2,8325 \\
60 & 4,2499 & 2,9823 & 2,5315 & 2,6232 \\
\hline
\end{tabular}

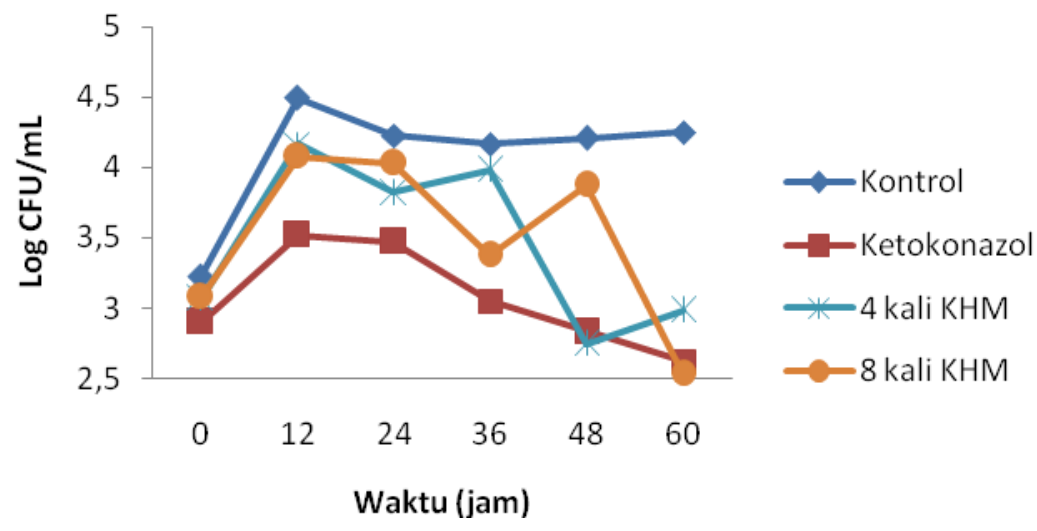

Gambar 1. Grafik efek fraksi etilasetat akar singawalang terhadap pertumbuhan Aspergillus niger 
Dilihat dari hasil tersebut, fraksi etilasetat menunjukkan aktivitas KHM lebih baik. Selanjutnya penentuan profil pertumbuhan dilakukan pada fraksi etilasetat dengan colony count menggunakan metode sebar pelat dan diinokulasikan setiap 12 jam setelah inokulum dipapar dengan fraksi etilasetat dan pembanding ketokonazol. Konsentrasi fraksi yang dibuat adalah 4 kali KHM dan 8 kali KHM.

Dari hasil tersebut terlihat bahwa profil pertumbuhan Aspergillus niger tidak konstan. Aktivitas antifunginya ada, tetapi belum dapat disimpulkan aktivitasnya fungistatik atau fungisida tetapi kurva cenderung menurun menunjukkan aktivitas fungisida.

\section{KESIMPULAN}

Fraksi etilasetat ekstrak etanol akar singawalang (Petiveria alliacea) memiliki efek antifungi terhadap Aspergillus niger tetapi belum dapat disimpulkan aktivitasnya fungistatik atau fungisida. Penelitian lanjutan diperlukan untuk memastikan hasil tersebut.

\section{DAFTAR PUSTAKA}

1. Benevides, J.P.C., Maria Claudia M.Y., Astrea M.G., Nidia F.R. dan V.S. Bolzani (2000) : Antifungal Polysulphides from Petiveria alliacea, Journal of Phytochemistry, 57, 743-747.
2. CLSI (2008) : M38-A2 Reference Method for Broth Dilution Antifungal Susceptibility Testing of Filamentous Fungi; Clinical and Laboratory Standard Institute, approved Standard-Second Edition.

3. Kayser, F.H., Bienz K.A., Eckert J. dan Zinkernagel, RN. (2005) : Medical Microbiology, Thieme, 348370.

4. Schwalbe, R., Moore L.S., Goodwin A.C. (2007) : Antimicrobial Susceptibility Testing Protocols, CRC Press Taylor \& Francis Group, Broken Sound Parkway NW, 173205, 220-228, 339-340.

5. Segismundo, A.B., Florendo B.E. dan Pablico A.R.P. (2008) : In vitro antifungal activity and Phytochemical Screening of Gouania javanica Miq. Leaves, UNP Research journal, Vol. XVII, 1-10.

6. Tierney L.M., McFee S.J. dan Papadakins M.A. (2005) : Current Medical Diagnosis and Treatment, McGraww Hill, 1485-1496. 